\title{
Oligodendroglial Process Formation is Differentially Affected by Modulating the Intra- and Extracellular Cholesterol Content
}

\author{
Matthias Schmitz • Sandra C. Signore • Inga Zerr • \\ Hans H. Althaus
}

Received: 16 March 2012 / Accepted: 4 June 2012 / Published online: 28 June 2012

(C) The Author(s) 2012. This article is published with open access at Springerlink.com

\begin{abstract}
Cholesterol is an essential component of eukaryotic plasma membranes and plays an important role in membrane organization and signaling processes. It is the major lipid component of detergent resistant caveolin-1 containing rafts which previously had been reported as a platform for nerve growth factor (NGF) signaling in oligodendrocytes (OL). Surprisingly, a knockdown of caveolin-1 attenuated the process formation of OL (Schmitz et al. J Neurosci Res 88:572588,2010 ), for which a loss of cholesterol could be responsible. In the present report, we could show that a caveolin-1 knockdown resulted in an elevation of cellular cholesterol level; it may indicate an important role of caveolin-1 in cholesterol trafficking to the plasma membrane. Treatment with exogenous PEG cholesterol, which was incorporated to the plasma membrane, supported oligodendroglial process formation, in particular when OL were stimulated by NGF. In this context we have found that OL express NPC1L1 (Niemann-Pick disease type C1-Like 1) which could modulate cholesterol uptake. In contrast, depletion of membrane-
\end{abstract}

M. Schmitz $\cdot$ H. H. Althaus

Max-Planck Institute of Experimental Medicine,

RU Neural Regeneration,

Hermann-Rein-Straße 3,

37075 Goettingen, Germany

M. Schmitz $(\bowtie) \cdot$ I. Zerr

Department of Neurology, University Medicine Göttingen,

Georg-August University Goettingen,

Robert-Koch-Straße 40,

37075 Goettingen, Germany

e-mail: matthias.schmitz@med.uni-goettingen.de

S. C. Signore

Department of Neurology, University Medicine Göttingen,

Georg-August University Goettingen,

Robert-Koch-Straße 40,

37075 Goettingen, Germany bound cholesterol diminished NGF-induced process formation concomitant with a reduced activity of p42/44 mitogenactivated protein kinases.

Keywords Caveolin-1 - Caveolin containing rafts . Cholesterol $\cdot$ Nerve growth factor $\cdot$ Niemann-Pick disease type C1-Like $1 \cdot$ Oligodendrocytes $\cdot$ TrkA

$\begin{array}{ll}\text { Abbreviations } & \\ \text { CCR } & \text { caveolin containing rafts } \\ \text { DIV } & \text { days in vitro } \\ \text { siRNA } & \text { small interfering RNA } \\ \text { MAPK } & \text { mitogen-activated protein kinases } \\ \text { M } \beta C D & \text { methyl-beta-cyclodextrin } \\ \text { NGF } & \text { nerve growth factor } \\ \text { NPC1L1 } & \text { Niemann-Pick disease type C1-Like 1 } \\ \text { OL } & \text { oligodendrocytes } \\ \text { PEG-600-chol } & \text { polyethylene glycol cholesterol } \\ \text { TrkA } & \text { tyrosine kinase A }\end{array}$

\section{Introduction}

A noteworthy characteristic of myelin is that it contains an exceptionally high content of lipids (over $70 \%$ of dry weight). More than $25 \%$ of the total lipid content is cholesterol, which represents the largest proportion of lipid molecules when based on a molar ratio (Norton and Cammer 1984). Cholesterol plays an important role in myelination (Saher et al. 2005), dendrite differentiation (Goritz et al. 2005) and synaptic activity (Mauch et al. 2001). It is endogenously synthesized, since plasma lipoproteins cannot pass the blood-brain barrier (Björkhem and Meaney 2004). Glial cells produce up to $90 \%$ of neural cholesterol. Hence glial cells are relevant mediators to cholesterol homeostasis in the CNS (Dietschy 
and Turley 2004). Astrocytes are suggested to support neurons with cholesterol (Nieweg et al. 2009). Oligodendrocytes (OL) are able to synthesize cholesterol by themselves, which is particularly important during myelinogenesis (Dietschy and Turley 2004), but they may be supported by astrocytes during this period.

In addition to these tasks, cholesterol can be detected in detergent-insoluble membrane microdomains (London and Brown 2000) such as caveolae. Their coat protein caveolin1 binds cholesterol (Murata et al. 1995) and requires cholesterol for oligomerization (Monier et al. 1996). Caveolin-1 is also involved in cholesterol transport processes (Fielding and Fielding 2006).

Previous studies had already reported that growth factors such as platelet derived growth factor or epidermal growth factor may use these cholesterol-enriched plasma membrane microdomains or caveolin containing rafts (CCR) as platforms for signaling (Paratcha and Ibanez 2002; Abulrob et al. 2004; Pike 2005; Gielen et al. 2006). In particular, NGFreceptors have previously been found in detergent-resistant CCR of PC12 cells (Huang et al. 1999; Peiro et al. 2000). Recently, it had been shown that the TrkA/NGF signaling pathway, by which pig OL can modulate their process regeneration (Althaus et al. 1992, 1997; Althaus and Klöppner 2006; Althaus et al. 2008), and the de novo synthesis of myelin proteins (Althaus 2004) is modulated by CCR (Schmitz et al. 2010). These findings indicate that cholesterol serves not only as an essential structural element of the plasma membrane but it may also be involved in cellular signaling processes as a component of these platforms.

A lack of cholesterol results in flattening of caveolae (Matveev et al. 2001; Parpal et al. 2001; Dreja et al. 2002); it also promotes an internalization of signaling complexes (Chang et al. 1992; Furuchi and Anderson 1998; Prevostel et al. 2000) and a translocation of signaling complexes outside caveolae; under the latter condition, signaling processes were impaired (Peiro et al. 2000).

In the present study, we have investigated the role of cholesterol on porcine oligodendroglial process formation, since a caveolin-1 knockdown had attenuated oligodendroglial process formation via NGF (Schmitz et al. 2010), for which cholesterol imbalance might be responsible. We could show that a caveolin-1 knockdown resulted in an elevation of cellular cholesterol level. In contrast, an upregulation of caveolin-1 via NGF provoked a cholesterol decrease, indicating a role for caveolin- 1 in cholesterol transport to the plasma membrane and in oligodendroglial cholesterol flux.

Treatment with exogenous cholesterol supported the formation of processes via NGF and the activation of $\mathrm{p} 42 / 44$ mitogen-activated protein kinases (MAPK) (Erk1 and 2). Rapid cholesterol depletion decreased NGF signaling, while moderate depletion of cholesterol via methyl-beta-cyclodextrin $(\mathrm{M} \beta \mathrm{CD})$ provoked an aggregation of $\mathrm{OL}$.
In search for additional components, which may play a role in oligodendroglial cholesterol trafficking, we could detect the presence of the cholesterol transport protein NPC1L1 (Niemann-Pick disease type C1-Like 1), a component, which was as yet reported for intestinal absorption of cholesterol as well as a modulator for the caveolin transport and localization (Davies et al. 2005).

\section{Materials and Methods}

All chemicals were of analytical grade where possible and obtained either from Sigma-Aldrich (Taufkirchen, Germany) or Merck (Darmstadt, Germany); culture media and fetal calf serum (FCS) were obtained from Biochrom (Berlin, Germany), Mezlocillin from Bayer (Leverkusen, Germany). ECL Western blotting detection kit came from Amersham (Freiburg, Germany).

\section{Cell Culture}

OL were isolated from adult pig brains and cultivated on polyD-lysine-coated Petri dishes or multiwell cultured plates by using an established protocol (Althaus et al. 1984; Bürgisser et al. 1988; Althaus and Klöppner 2006). Briefly, the white matter of mature pig (domestic, 6 months old) brains was dissected, minced, and sieved through nylon sieves of descending pore size. After that, cells were collected after centrifugation of the cell tissue suspension onto a discontinuous Percoll gradient, seeded and cultured on poly-D-lysinecoated Petri dishes or multiwall culture plates. The culturing protocol was as previously described (Althaus et al. 1991), except that the FCS in the culture medium was reduced to $5 \%$; transmission electron microscopy and immunocytochemical criteria identified the cells as mature $\left(\mathrm{GC}^{+}, \mathrm{MBP}^{+}, \mathrm{PLP}^{+}\right.$, $\mathrm{MOG}^{+}$) OL (Althaus et al. 1991; Althaus and Siepl 1997; Althaus and Klöppner 2006); $\mathrm{A}_{2} \mathrm{~B}^{+}$, $\mathrm{GFAP}^{+}$, or $\mathrm{OX}_{4}{ }^{2+}$ cells were initially observed rarely if at all (Althaus and Siepl 1997); anti-MOSP IgM (Chemicon/Millipore, Schwalbach, Germany) diluted 1:1,000 was routinely used to specifically label OL (Dyer and Matthieu 1994) in this study.

Morphometric Measurement of the Oligodendroglial Fibers

Morphometric evaluation of oligodendroglial process formation and process length occurred according to a previous protocol (Althaus et al. 1991). Briefly, phase contrast photographs were taken at random positions in the culture dishes (four different preparations). Photos were magnified to a suitable size. The determination of the oligodendroglial processes formation was performed by computing the average length of fibers per cell in arbitrary/relative units (r. U.) by a map measurer. 
Immunocytochemical Analysis

The following antibodies were used to visualize the indicated proteins: polyclonal anti-caveolin IgG (Transduction Laboratories, Lexington, USA) diluted 1:1,000; polyclonal anti-NPC1L1 (Novus Biologicals Corporation, Littleton, USA), diluted 1:500 for Western blot and 1:100 for immunocytochemistry; monoclonal anti-beta actin IgG (Abcam, Cambridge, UK) diluted 1:10,000; anti-MOSP IgM (Chemicon/Millipore) 1:500. Alexa Fluor 488 conjugated goat anti-mouse IgM and IgG were used as secondary antibodies (Molecular Probes/Invitrogen, Darmstadt, Germany) diluted 1:1,000; ECL anti-rabbit and anti-mouse IgG, horseradish peroxidase linked (Amersham, Freiburg, Germany) diluted 1:1,000.

For immunochemical staining cells were fixed in methanol/acetic acid (9:1) and treated with $0.1 \%$ Triton X-100; antibody incubations took around $1 \mathrm{~h}$ at room temperature.

\section{Detergent-Free Enrichment of Caveolin-Containing Rafts}

A slightly modified version of the sodium carbonate method of Song et al. (1996) was used to enrich CCR. Very briefly, $50 \times 10^{6}$ porcine OL $(8 \mathrm{DIV})$ were scraped into $2 \mathrm{~mL}$ sodium carbonate $\mathrm{pH} 11.0$ and homogenized by an all-glass Dounce homogenizer. The cellular nuclei were removed by centrifugation at $1,000 \times g$. The homogenate was adjusted to $45 \%$ sucrose/MBS buffer ( $25 \mathrm{mM}$ MES and $0.15 \mathrm{M} \mathrm{NaCl}, \mathrm{pH}$ 6.5) and placed at the bottom of a Beckman centrifuge tube; on top, a discontinuous $5-35 \%$ sucrose gradient $(4 \mathrm{~mL}$ of $35 \%$ sucrose and $4 \mathrm{~mL}$ of $5 \%$ sucrose in MBS containing $250 \mathrm{mM}$ sodium carbonate) was formed. After centrifugation for $22 \mathrm{~h}$ at $39,000 \mathrm{rpm}$ (SW 41 rotor, Beckman), $12 \times 1 \mathrm{~mL}$ fractions were obtained, washed in MBS buffer and used for analysis. Afterwards, we determined the amount of caveolin-1 and cholesterol in CCR-enriched fractions 4-6 in comparison to non-CCR fractions $1-3$ and 7-12 (Schmitz et al. 2010).

\section{Cholesterol Treatment and Depletion}

To investigate the influence of cholesterol on the oligodendroglial process formation, we exposed 8 DIV OL to the water-soluble derivate polyethylene glycol-600 cholesterol (PEG-600-chol) (Sigma-Aldrich, Deisenhofen, Germany). The PEG-600-chol was added to the cell media in a concentration of $100 \mu \mathrm{g} / \mathrm{mL}$ for the indicated times, PEG-600 served as a control. For acute cholesterol depletion, cells were treated with methyl-beta-cyclodextrin (M $\beta C D)$ (Sigma-Aldrich) $(10 \mathrm{mM})$ for $45 \mathrm{~min}$. Long-term experiments with a moderate cholesterol depletion were carried out by using $\mathrm{M} \beta C D$ in a concentration of $3 \mathrm{mM}$.

\section{Determination of Cholesterol}

The cellular cholesterol level was measured by the Amplex Red Cholesterol Assay (Molecular Probes/Invitrogen) according to the manufacturer's instructions and by using an established protocol (Amundson and Zhou 1999). This assay was conducted in a 96-well microplate using $100 \mu \mathrm{L}$ of reaction volume per well. After extraction of the cellular cholesterol according the modified protocol from Gamble (Gamble et al. 1978), we dissolved the extracted cholesterol in $50 \mu \mathrm{L}$ reaction buffer containing $0.5 \mathrm{M} \mathrm{K}_{2} \mathrm{PO}_{4}, 0.25 \mathrm{M}$ $\mathrm{NaCl}, 25 \mathrm{mM}$ gallic acid, and $0.5 \%$ Triton X-100. The enzyme reaction started after addition of $50 \mu \mathrm{L}$ working solution, containing $300 \mu \mathrm{M}$ Amplex Red reagents (10acetyl-3.7-dihydroxyphenoxazin), $2 \mathrm{U} / \mathrm{mL}$ HRP, $2 \mathrm{U} / \mathrm{mL}$ cholesterol oxidase, and $2 \mathrm{U} / \mathrm{mL}$ cholesterol esterase. After incubated at $37^{\circ} \mathrm{C}$ for $30 \mathrm{~min}$, fluorescence intensities were measured using a fluorescence microplate reader.

Immunocytochemical Imaging of Fluorescent-Conjugated Cholesterol

Fluorescein-polyethylenglycol-50 cholesterol (fPEG-chol), a kind gift of Dr. Kobayashi (RIKEN, Saitawa, Japan), was used to monitor cholesterol uptake. 8 DIV OL were treated with fPEG-chol $(1 \mu \mathrm{M})$ for $15 \mathrm{~min}$ and $24 \mathrm{~h}$. The uptake and internalization of fPEG-chol could be demonstrated by fluorescence microscopy.

\section{Western Blotting}

OL were pre-treated with $1 \mathrm{mM}$ sodium orthovanadate for $1 \mathrm{~h}$, washed with PBS (phosphate-buffered saline) containing a mixture of inhibitors $(1 \mathrm{mM}$ sodium orthovanadate, $1 \mathrm{mM}$ sodium fluoride, $1 \mathrm{mM}$ phenylmethylsulfonyl fluoride, $1 \mu \mathrm{g} / \mathrm{mL}$ aprotinin, and $1 \mu \mathrm{g} / \mathrm{mL}$ leupeptide) and harvested by scraping on ice. Cell lysates were dissolved in $2 \% \mathrm{SDS}$, containing all inhibitors, for $30 \mathrm{~min}$, denaturated in sample buffer (containing mercaptoethanol) and heated at $95{ }^{\circ} \mathrm{C}$ for $2 \mathrm{~min}$. Protein samples of equivalent protein content $(20 \mu \mathrm{g} / \mathrm{lane}$; protein determination according to Neuhoff et al. 1979) were separated by $10-15 \%$ sodium dodecyl sulfate-polyacrylamide gel electrophoresis (SDS-PAGE) according to Laemmli (1970) and transferred to polyvinylidene difluoride (PVDF) membranes (Amersham). The PVDF membranes were incubated with $5 \%$ dried milk in PBS and $0.1 \%$ Tween-20 for $1 \mathrm{~h}$ at room temperature and afterwards probed with the antibodies of interest overnight at $4{ }^{\circ} \mathrm{C}$. ECL antibodies from Amersham were utilized as secondary antibodies. The bands were visualized by the enhanced chemiluminescence (ECL) detection system according to the manufacturer's instructions. 
In-Gel Mitogen-Activated Protein Kinase Assay

Cells were exposed to NGF for the times indicated. The cell lysates were separated by SDS-PAGE using a gel in which $10 \% \mathrm{MBP}$ (myelin basic protein) was incorporated; renatured MAPK (Erks) activity was detected following a modified protocol (Althaus et al. 1997) of (Virdee and Tolkovsky 1995). The gel was incubated in assay buffer for $60 \mathrm{~min}$ at $30^{\circ} \mathrm{C}$ allowing the transfer of radioactive phosphor to myelin basic protein; not incorporated radioactivity was removed by washing the gel several times in $5 \%$ TCA containing $1 \%(w / v)$ tetrasodium pyrophosphate. Afterwards, the gel was dried overnight and subjected to autoradiography at $-70{ }^{\circ} \mathrm{C}$, using an RX-Fuji X-ray film.

\section{Transfection of Pig OL and Caveolin Knockdown}

Our experiments were based on findings of $\mathrm{Ge}$ and Pachter (2004) who reported about a half-life of astroglial caveolin-1 in between 12 and $18 \mathrm{~h}$, which makes attempts to knockdown caveolin-1 reasonable. Caveolin-1 siRNAs were synthesized by Qiagen (Hilden, Germany) based upon the sequence of porcine caveolin-1 (PubMed Accession-number AY490204) with all characteristics of siRNA targeting constructs. In preliminary experiments (Schmitz et al. 2010), a panel of transfection reagents was tested by using unspecific fluorescent siRNA: Lipofectamin (Invitrogen), Oligofectamin (Invitrogen), jetSI-Endo (Biomol, Hamburg, Germany), Gene Silencer (PQ-Lab Biotechnologies, Erlangen, Germany), and RNAiFect (Qiagen); efficient transfection and cell vitality were the decisive criteria in our hands, best results were finally obtained with 3-4 $\mu \mathrm{L}$ jetSIEndo/mL and caveolin-1 specific siRNA (40-60 $\mathrm{nM}$ ) solved in $200 \mu \mathrm{L}$ Gibco OptiMEM (Invitrogen); stable
siRNA complexes were formed after 15-20 min and added to the culture medium (MEM, $2 \%$ FCS) in which the cells were incubated for $5-8 \mathrm{~h}$ or overnight. Thereafter, the medium was replaced by fresh culture medium containing $5 \% \mathrm{FCS}$.

\section{Signal Quantification and Statistical Analysis}

The quantification of the staining intensities of all Western blots and MAPK in-gel kinase assays were performed by the densitometric software Scion Image. Using the statistic program Graph Pad Prism 4 the ratios of different samples were tested for significance utilizing the two-sided unpaired Student's $t$ test. All $p$ values below $0.05(* p<0.05)$ are considered as significant. The standard error of the mean (SEM) was calculated to assess the variations between different samples under the same conditions and depicted as error bars. The error bars represent the SEM of at least three independent attempts.

\section{Results}

\section{Uptake of Exogenous Cholesterol}

Polyethylenglycol cholesteryl ethers are a unique group of non-ionic amphipathic cholesterol derivates. These compounds are soluble in water but retain many of the structural aspects of cholesterol (Ishitsuka et al. 2005). To visualize a cholesterol uptake in living cells, a fluorescein ester of PEGchol that contains a fluorescein on the distal end of the PEG chain was used (Ishitsuka et al. 2005).

Cells were incubated with fPEG-chol $(1 \mu \mathrm{M})$ to monitor the dynamics of fPEG-chol uptake. Primarily oligodendroglial plasma membranes were stained; however, relative low
Fig. 1 Uptake of PEG-chol in pig OL. a OL were exposed to fPEG-chol $(1 \mu \mathrm{M})$. Portions of fPEG cholesterol distributed within the oligodendroglial plasma membrane after $15 \mathrm{~min}$ (1) and reached $24 \mathrm{~h}$ later cellular compartments (2), as demonstrated by immunofluorescence microscopy. b Extracellular exposure to PEG-600-chol $(100 \mu \mathrm{g} / \mathrm{mL})$ resulted in an approximately $10-15 \%$ increase of total cholesterol level after $15 \mathrm{~min}$ and in a $30-35 \%$ enhancement after $24 \mathrm{~h}$. Quantification of total cellular cholesterol amount was performed by utilizing Amplex Red Cholesterol Assay. $P<0.05$ was considered significant. Values are depicted as mean \pm SEM a
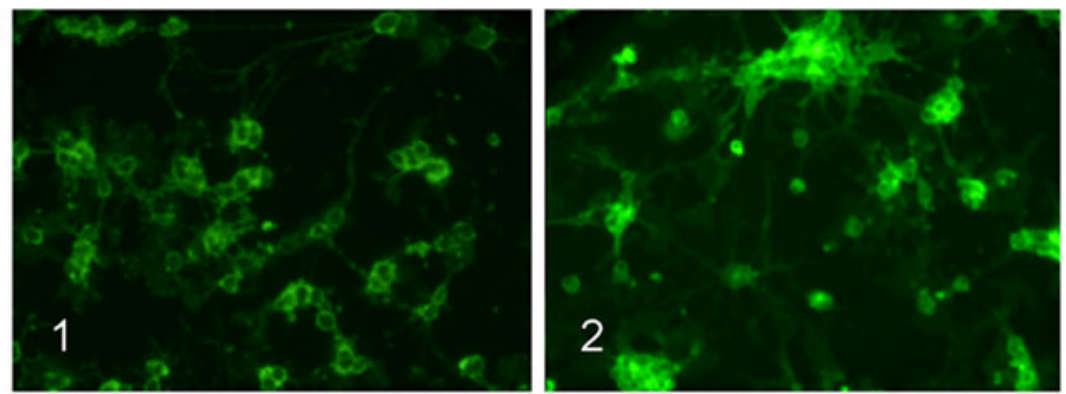

b

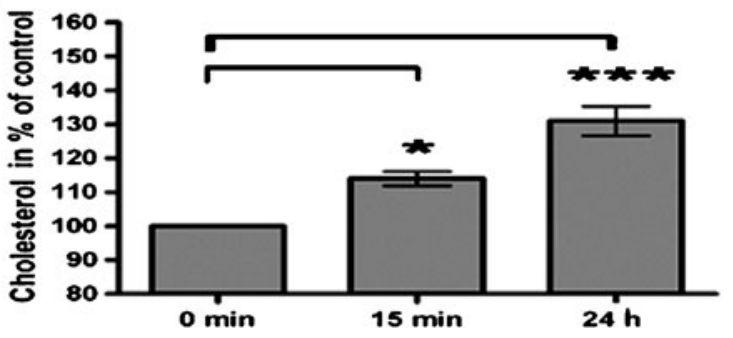


Fig. 2 Effect of cholesterol on oligodendroglial process

formation. a The morphometric evaluation of the oligodendroglial process formation (4) revealed that a treatment of OL (8 DIV) with PEG-600-chol $(100 \mu \mathrm{g} / \mathrm{mL})$ for $48 \mathrm{~h}(3)$ resulted in a significantly enhanced process formation compared to cells treated with PEG-600 (2), which behaved similar to untreated cells (1). b OL, preincubated with PEG-600-chol for $24 \mathrm{~h}$, formed after $24 \mathrm{~h}$ NGF exposure significantly more processes (3), when compared to untreated control cells (1) or to cells treated with NGF for $24 \mathrm{~h}$ (2). An approximately twofold increase of process formation in NGF plus PEG-600-chol-treated cells was verified by morphometric evaluation (4). c An in-gel MAPK assay showed that the NGF-induced activation of MAPK (Erk1 and Erk2) after $4 \mathrm{~h}$ (lane 3) was significantly increased when cells were preincubated with cholesterol for $24 \mathrm{~h}$ (lane 2). $P<0.05$ was considered significant. Values are depicted as mean \pm SEM a
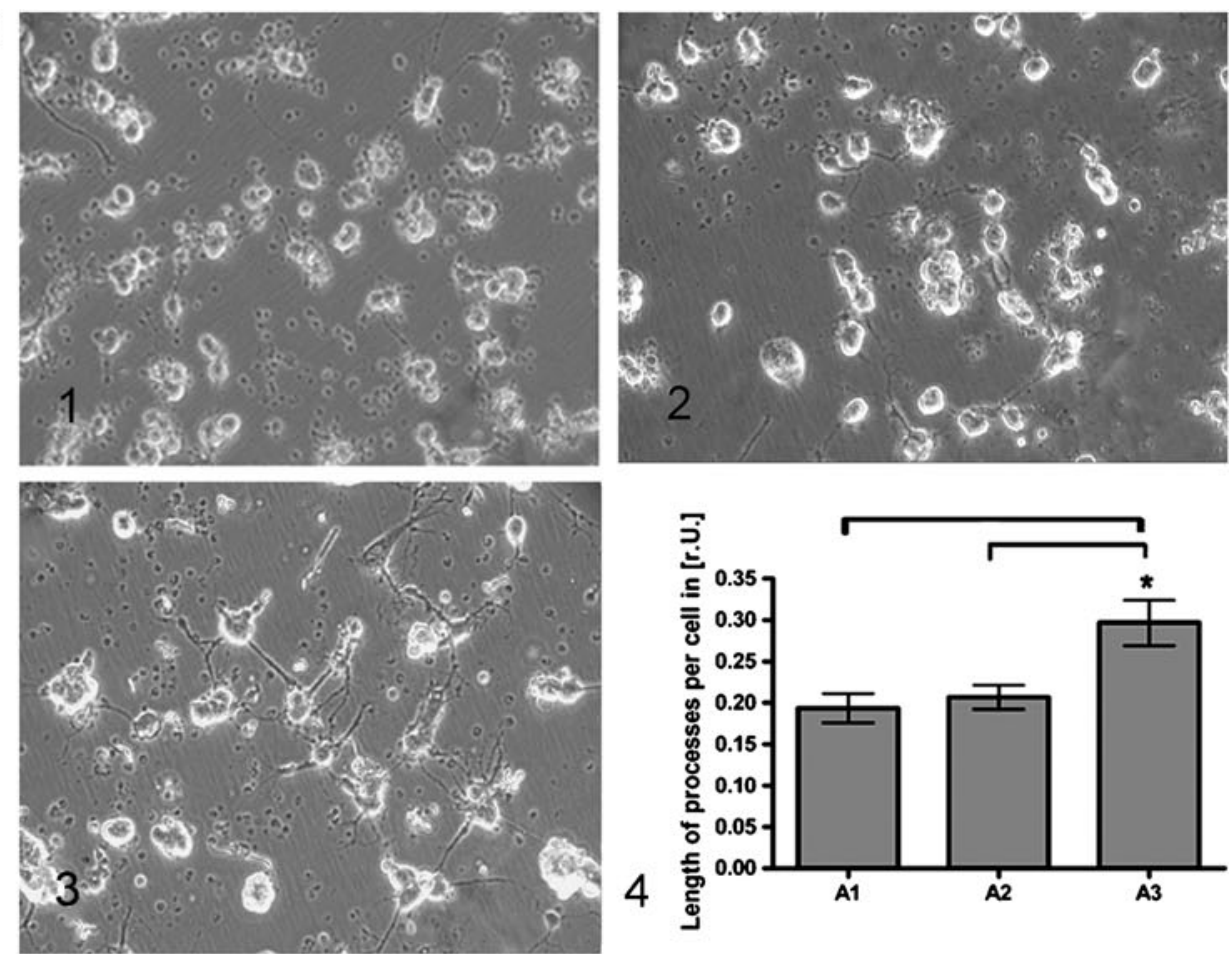

b
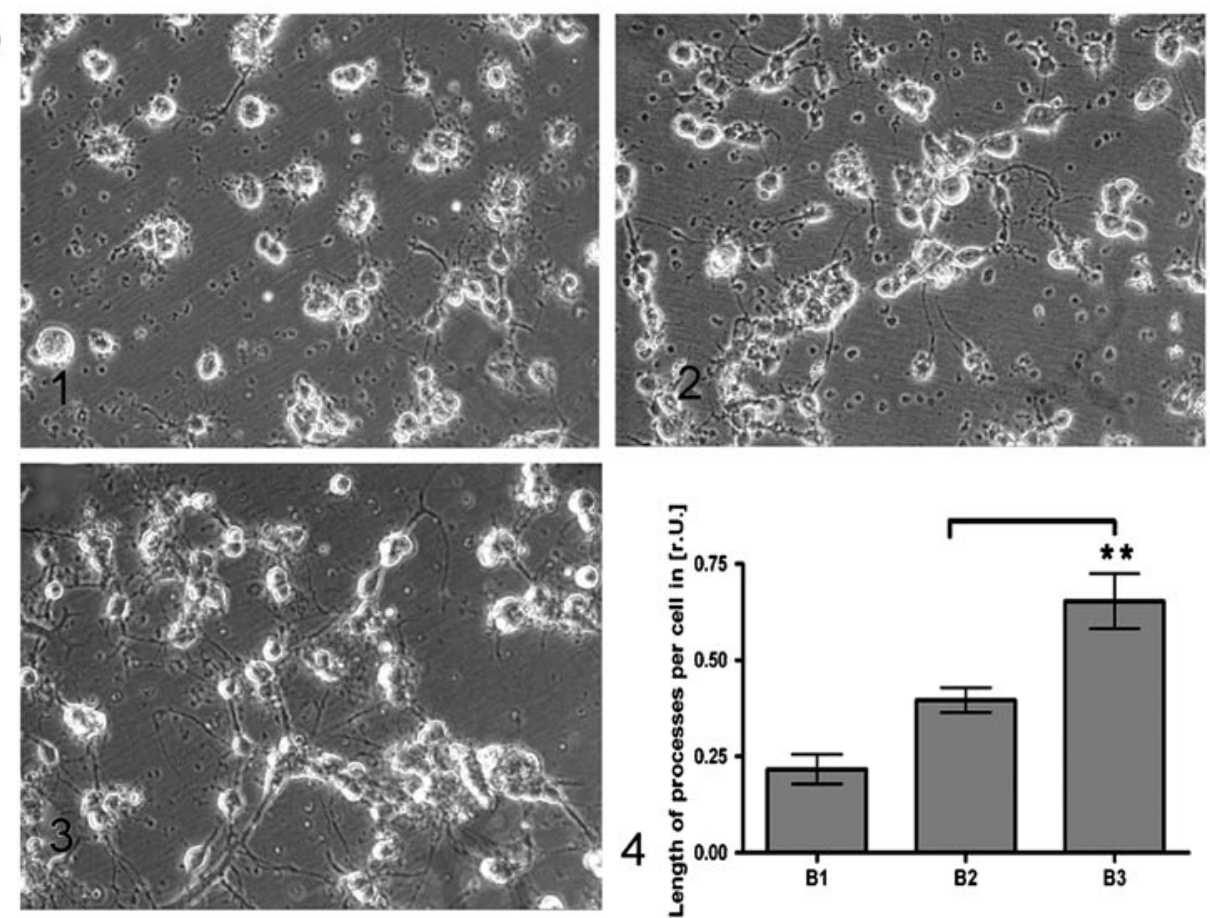

C
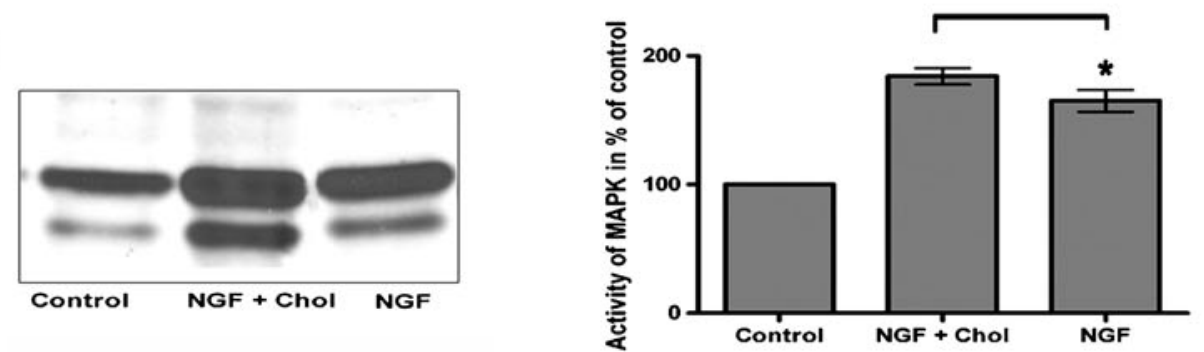
amounts of fPEG-chol had already passed the plasma membrane after 15 min (Fig. 1a, 1); 24 h later, fPEG-chol was distributed to the plasma membrane and cellular compartments (Fig. 1a, 2). Supplementing the culture medium with exogenous PEG-600-chol $(100 \mu \mathrm{g} / \mathrm{mL})$ resulted in an increase of the cellular cholesterol level of approximately $10-15 \%$ after $15 \mathrm{~min}$ and of 30-35\% after $24 \mathrm{~h}$ (Fig. 1b). A tendency to form aggregates of $\mathrm{OL}$ as reported for ascites tumor cells when the cells were enriched in cholesterol (Haeffner et al. 1984) could not be observed. PEG-600 alone did not affect the basic oligodendroglial cholesterol content of $10-20 \mu \mathrm{g} / \mathrm{mg}$ OL protein (Klopfleisch et al. 2008).

Cholesterol, Exogenously Added, Promotes Oligodendroglial Process Formation and NGF Signaling

OL (8 DIV) were exposed to PEG-600-chol $(100 \mu \mathrm{g} / \mathrm{mL})$ and PEG-600 $(100 \mu \mathrm{g} / \mathrm{mL})$. The length of processes per cell was determined ("Materials and Methods"). We observed that process formation of PEG-600-chol-treated cells was significantly increased after $48 \mathrm{~h}$ (Fig. 2a, 3) compared to PEG-600-treated cells $(p<0.05)$ (Fig. 2a, 2) of which the morphology was comparable to untreated cells (Fig. 2a, 1). PEG-600-chol exposure also did increase MAPK activity; however, not significantly (data not shown).

Next, we examined the impact of cholesterol in combination with NGF. A significant increase of the length of oligodendroglial processes could be observed in 8 DIV OL, treated with PEG-600-chol $(100 \mu \mathrm{g} / \mathrm{mL})$ for $48 \mathrm{~h}$ plus NGF $(100 \mathrm{ng} / \mathrm{mL})$ for the last $24 \mathrm{~h}$ (Fig. 2b, 3), compared to NGF-treated cells without additional cholesterol (Fig. 2b, 2). Untreated control cells showed a basal length of processes (Fig. 2b, 1).

The ability of PEG-600-chol to promote oligodendroglial process formation under NGF was underlined by an increase of the activity of MAPK (Erk1 and Erk2), which was significantly more activated when NGF was used in combination with PEG-600-chol as compared to NGF-treated and untreated cells (Fig. 2c).

Cholesterol Depletion Affects the Oligodendroglial Process Formation and Induces Cell Aggregation

$\mathrm{M} \beta \mathrm{CD}$ is a cholesterol-binding drug which efficiently removes cholesterol from the plasma membrane (Christian et al. 1997). A mild depletion of cholesterol using $3 \mathrm{mM} \mathrm{M} \beta \mathrm{CD}$ reduced the cellular cholesterol content to approximately $75 \%$ after $24 \mathrm{~h}$ compared to that of untreated control cells. A higher and rapid depletion of oligodendroglial cholesterol was achieved by a treatment with $10 \mathrm{mM} \mathrm{M} \beta \mathrm{CD}$ for $45 \mathrm{~min}$ which resulted in a decrease of approximately $60 \%$ cholesterol (Fig. 3a).

Rapid cholesterol depletion affected the NGF-induced process formation. Pretreatment of OL with $\mathrm{M} \beta \mathrm{CD}(10 \mathrm{mM})$ for 45 min impaired the NGF-induced oligodendroglial process
Fig. 3 Depletion of cholesterol by $M \beta C D$. a Total cellular cholesterol levels in OL were decreased after incubation with $\mathrm{M} \beta C D(3 \mathrm{mM})$ for approximately $25 \%$ and with $\mathrm{M} \beta \mathrm{CD}(10 \mathrm{mM})$ for approximately $60 \%$. b Cholesterol deficiency provoked a significantly decreased process formation after NGF exposure for $48 \mathrm{~h} \mathrm{(2),} \mathrm{compared} \mathrm{to} \mathrm{OL}$ treated with NGF solely (3). The addition of cholesterol compensated this effect (4). Untreated OL showed a basal fiber generation (1). The morphometric evaluation revealed an approximately 2.5 to threefold decrease of process formation in cholesterol deficient cells after NGF exposure (5). c An in-gel MAPK assay revealed that the NGF-induced activation of MAPK (Erk1 and Erk2) was reduced in cholesterol depleted OL, which were preincubated with $\mathrm{M} \beta C D(10 \mathrm{mM})$ for $45 \mathrm{~min}$ and afterwards exposed to NGF for $4 \mathrm{~h}$, compared to cells exposed to NGF solely. d Long-term exposure of OL with $\mathrm{M} \beta \mathrm{CD}$ $(3 \mathrm{mM})$ caused a retraction of OL processes after $24 \mathrm{~h}$ (1) compared to untreated control cells $(1$, inset $)$ and an aggregation after $72 \mathrm{~h}(2)$. After removing $\mathrm{M} \beta \mathrm{CD}$ and addition of PEG-600-chol $(100 \mu \mathrm{g} / \mathrm{mL})$ cells migrated out of the aggregates (3-5). Immunostaining with anti-MOSP revealed that the migrated cells were still mature OL (6). $P<0.05$ was considered significant. Values are depicted as mean \pm SEM

formation after $48 \mathrm{~h}$ markedly (Fig. 3b, 2). Cells solely stimulated with NGF showed the expected NGF effect (Fig. 3b, 3). The addition of PEG-600-chol to the NGF-containing medium could compensate the cholesterol depletion (Fig. 3b, 4). Untreated control OL developed a basic number of short processes during this time period (Fig. 3b, 1).

In this context, we analyzed the effect of an acute cholesterol depletion on downstream components of the NGF signaling cascade. We could show that a cholesterol deficiency did not only affect the morphological appearance of OL but also the NGF signaling cascade: the activation of p42/44 MAPK (Erk1 and Erk2) was significantly reduced after NGF exposure for $4 \mathrm{~h}$ compared to untreated cells (Fig. 3c).

While almost all experiments with $\mathrm{M} \beta \mathrm{CD}$ use higher concentrations of $\mathrm{M} \beta \mathrm{CD}$ in a relative short time, we were interested to know how OL react on moderate cholesterol depletion within a prolonged time frame. We incubated OL with $3 \mathrm{mM} \mathrm{M} \beta \mathrm{CD}$ for $72 \mathrm{~h}$. A decreased level of cholesterol of approximately $25 \%$ induced a retraction of oligodendroglial processes within $24 \mathrm{~h}$ (Fig. 3d, 1); $72 \mathrm{~h}$ later an aggregation of the cells has occurred (Fig. 3d, 2). Addition of PEG-600-chol (plus removal of $\mathrm{M} \beta \mathrm{CD}$ ) dispersed oligodendroglial aggregates; after $24 \mathrm{~h}$ (Fig. 3d, 3) to $72 \mathrm{~h}$ (Fig. 3d, 4), some cells detached from each other, 7 days later the aggregates were completely dispersed (Fig. 3d, 5). Immunostaining with anti-MOSP, an oligodendroglial specific marker (Dyer and Matthieu 1994), demonstrated that the cells, released from the aggregates, were still mature OL (Fig. 3d, 6). In contrast, OL started to detach from the dish when $\mathrm{M} \beta \mathrm{CD}$ was removed without adding PEG-600-chol.

\section{Role of Caveolin-1 Knockdown on Cholesterol} Homeostasis

Since caveolin-1 acts also as a cholesterol transport protein (Fielding et al. 1999), we were interested to know as to whether 
a

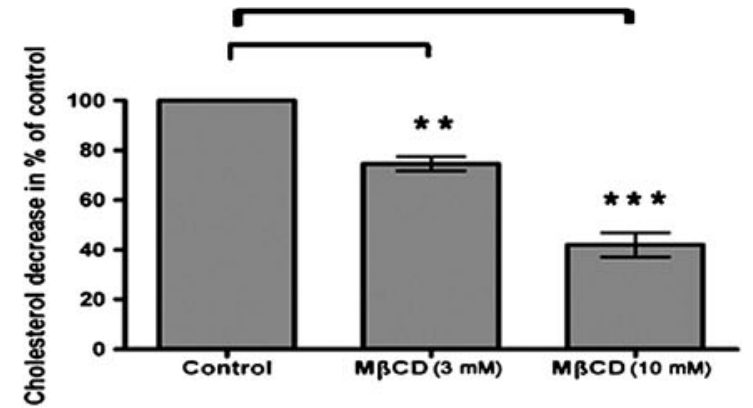

b
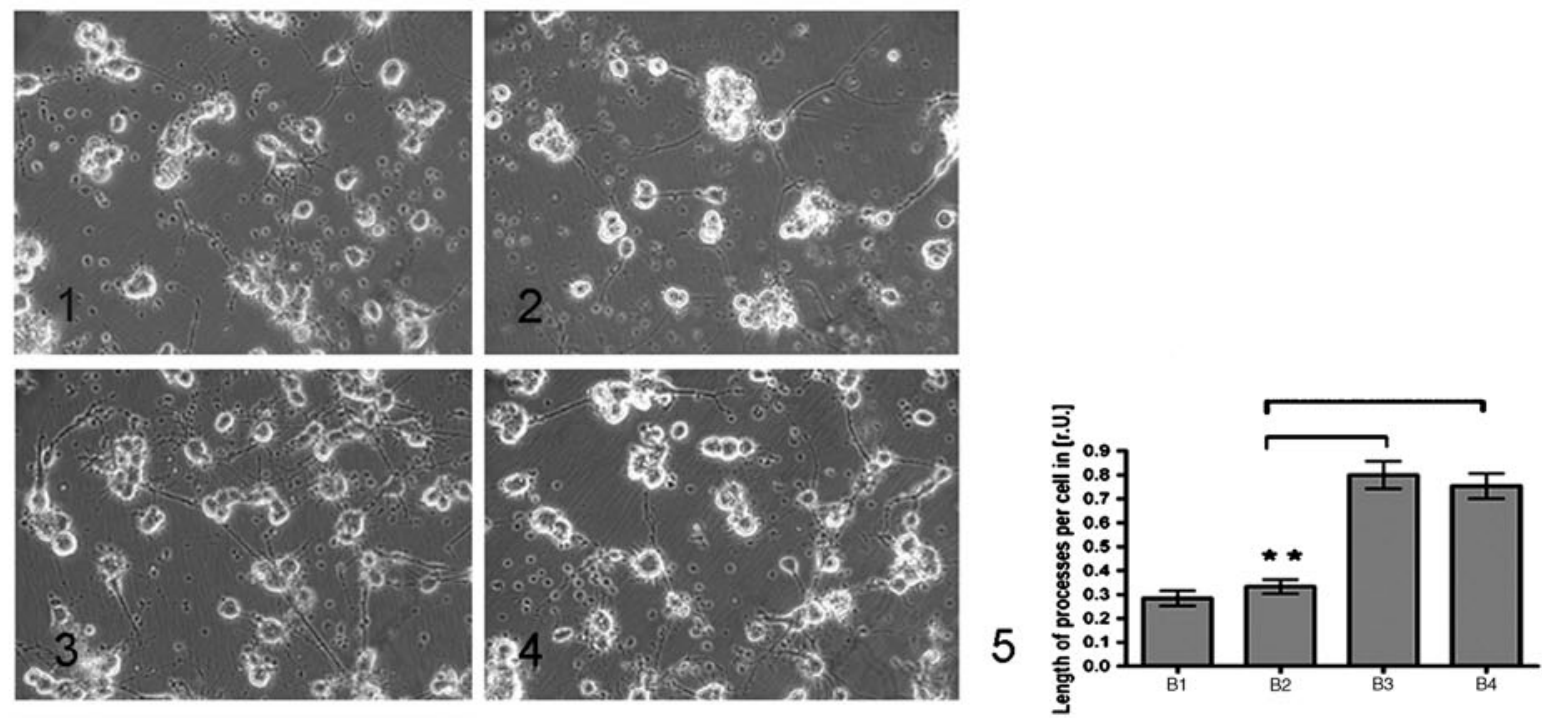

C

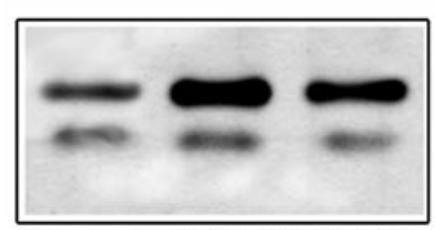

Control NGF NGF+MßCD
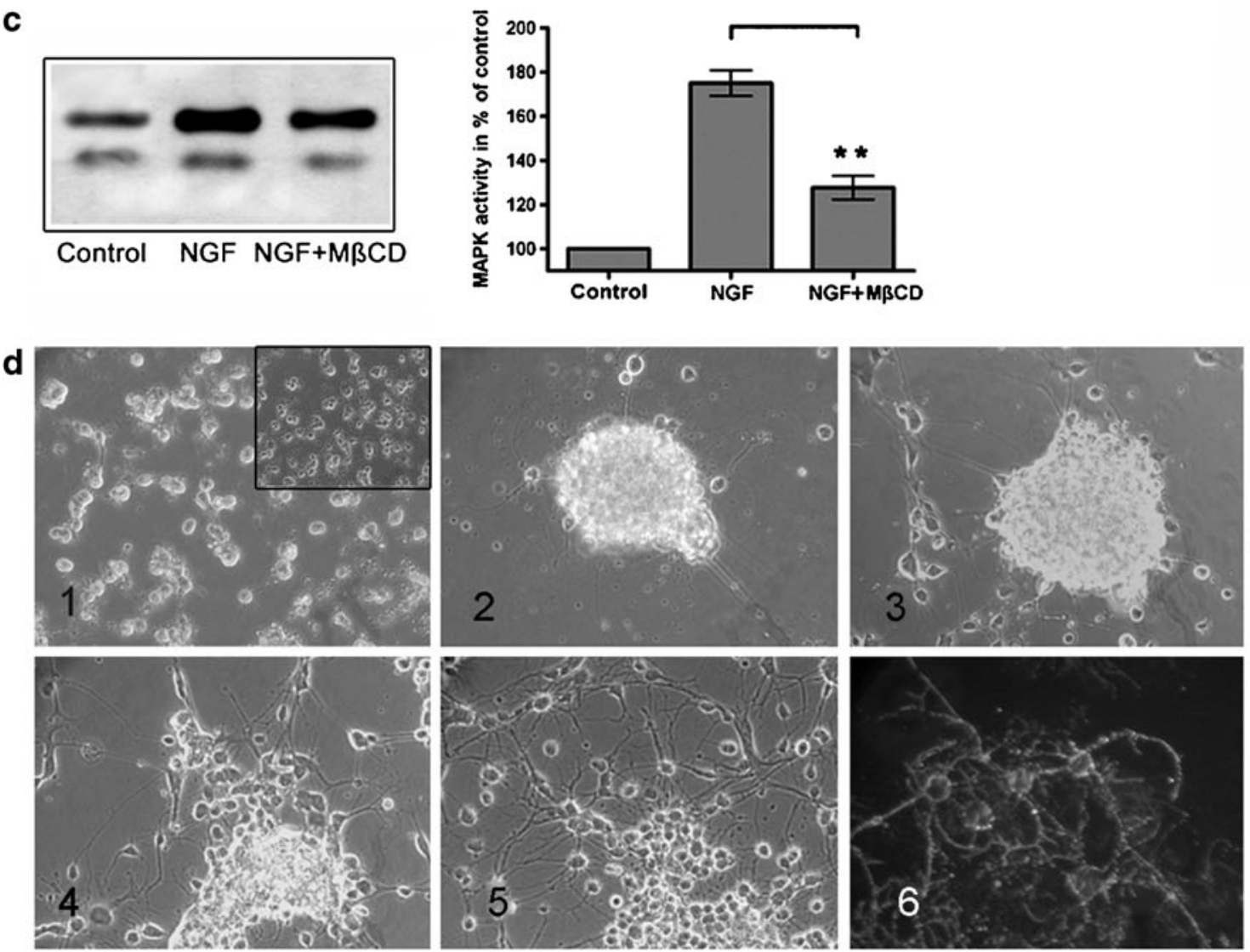
a knockdown of oligodendroglial caveolin-1 (Schmitz et al. 2010) might affect the cholesterol content in pig OL. Caveolinenriched membrane fractions were isolated by utilizing the sodium carbonate method of Song et al. (1996). We pooled the caveolin-enriched fractions (4-6) versus the remaining fractions (fractions $1-3 ; 7-12$ ) and determined the cholesterol level as well as the caveolin-1 expression. Approximately 60 $65 \%$ of the cellular cholesterol and $70-75 \%$ of the amount of caveolin-1 were located in the caveolin-enriched fractions (Fig. 4a, 1 and 2). Treatment with NGF resulted in a marked upregulation of caveolin-1 expression after $48 \mathrm{~h}$ (Fig. 4b; 1, inset) and as shown previously (Schmitz et al. 2010). At the same time point, we observed that the cellular cholesterol amount was reduced significantly (Fig. 4b, 1).

Specific short interference RNAs (siRNA) were a valuable tool to downregulate the expression of caveolin-1. An effective knockdown of caveolin-1 after $48 \mathrm{~h}$ was shown by Western blotting (Fig. 4b; 2 , inset); $\beta$-actin served as an internal control. Cells, treated with non-specific (NS)-siRNA under the same conditions, expressed caveolin-1 (Fig. 4b, 2, inset) similar to untreated OL (data not shown).

Interestingly, a caveolin-1 knockdown induced a significant enhancement of the cellular cholesterol content 2496 h post-transfection (Fig. 4b, 2).

In this context, we could show for the first time that NPC1L1 (Niemann-Pick C1-Like 1, MW 145 kDa), known for serving as a plasma membrane anchored cholesterol sensing receptor in the intestine (Better and Yu 2010; Davies et al. 2005), is present in pig OL (Fig. 4c, inset). It seems to be localized to the plasma membrane and to intracellular compartments as revealed by immunolabeling (Fig. 4c).

\section{Discussion}

Although much knowledge has accumulated concerning the regulation of cholesterol in the human body, only less information is available about the role of oligodendroglial cholesterol. OL play an essential role in myelin biogenesis (Saher and Simons 2010); cholesterol is an important compound of the resulting myelin sheaths.

\section{Role of Cholesterol in Oligodendroglial Signal Transduction}

In our study, we were interested to know as to whether cholesterol participates in oligodendroglial NGF/TrkA signaling which affects the myelination process (Althaus et al. 1997). Treatment of pig OL with external cholesterol derivates revealed that the cells were able to incorporate cholesterol into the plasma membrane followed by a slow cellular distribution; a course already reported for other cells (Sato et al. 2004). We observed that an increase of the oligodendroglial membrane cholesterol content induced an enhanced process formation,
Fig. 4 Influence of caveolin-1 on the cellular cholesterol level. a CCR were isolated according the sodium carbonate method of Song et al. (1996). Cholesterol content and caveolin-1 expression were determined; approximately $60 \%$ of the cellular cholesterol and $75 \%$ of caveolin- 1 were located in the CCR-enriched fractions $(1,2)$. b A treatment with NGF induced an upregulation of caveolin-1 expression after $48 \mathrm{~h}$, shown by Western blotting $(1$, inset), while the cellular cholesterol content decreased simultaneously (1). Knockdown of caveolin-1 gene expression was demonstrated by Western blotting $48 \mathrm{~h}$ post-transfection $(2$, inset). The oligodendroglial cholesterol content was significantly enhanced 24$96 \mathrm{~h}$ post-transfection (2). c Immunostaining with anti-NPC1L1 and Western blotting (inset, lane a: NPC1L1) revealed the expression of this cholesterol transport protein in pig OL. $P<0.05$ was considered significant. Values are depicted as mean \pm SEM

which was even more accelerated when the cells were exposed to NGF for $24 \mathrm{~h}$. This finding indicates that the actual cellular cholesterol level affects the NGF signaling cascade.

A cellular fractionation according to the sodium carbonate method (Song et al. 1996) showed that most of the oligodendroglial cholesterol ( $\sim 60 \%)$ and caveolin-1 ( $75 \%)$ could be detected in the CCR-enriched fractions in addition to TrkA and MAPK (Schmitz et al. 2010). These data suggest that cholesterol may be involved in the oligodendroglial signaling by regulating the composition of CCR, which had been described previously to play a modulating role during the oligodendroglial process formation via NGF (Schmitz et al. 2010, 2011). Cholesterol is important for the function and organization of membrane proteins and receptors (Pucadyil and Chattopadhyay 2006). This effect could either be due to a specific molecular interaction between cholesterol and signaling molecules or due to alterations of the membrane fluidity (Kwik et al. 2003; Byfield et al. 2004). The residue 94-101 within the caveolin scaffolding domain (82-101) contains a cholesterol recognition sequence that binds free cholesterol (Epand et al. 2005). The binding of cholesterol to caveolin plays a relevant structural and functional role in CCR (Pike 2005; Thomas and Smart 2008). Structurally, it is needed as a stabilizing structure element of lipid rafts or CCR and to maintain the invaginated form of caveolae. Functionally, cholesterol may facilitate the ability of some proteins to associate with CCR and to form the basis for specific clustering events which is responsible for signal transduction and membrane trafficking (Brown and London 1998; Incardona and Eaton 2000). Moreover, cholesterol exposure may result in an increase in cell-surface caveolae by induction of caveolin-1 synthesis (Fielding et al. 1997; Bist et al. 1997) or an enhanced transfer of caveolin-1 from cellular pools to CCR (Thyberg 2002).

Moderate Cholesterol Depletion Induces Aggregation of OL

The pharmaceutical use of cyclodextrins has been discussed in several articles (Rao and Stella 2003; Loftsson and Brewster 2010). Cyclodextrins enhance the solubility and chemical 
a

1

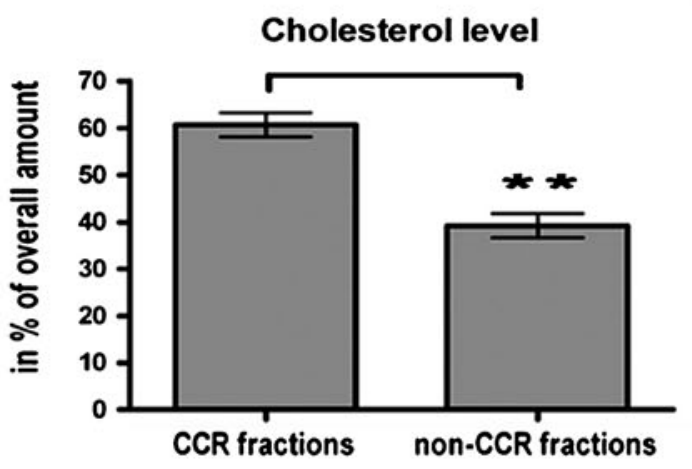

b

1

Control NGF 48h
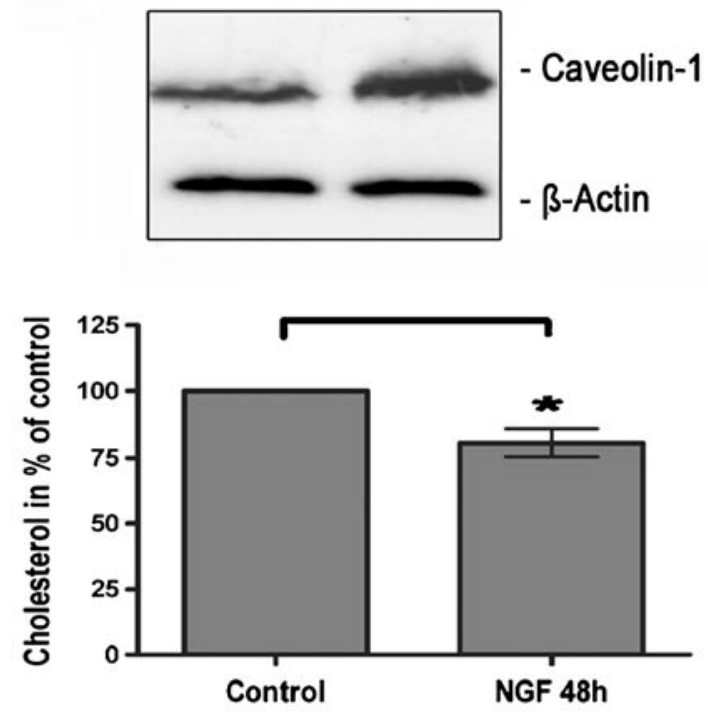

C

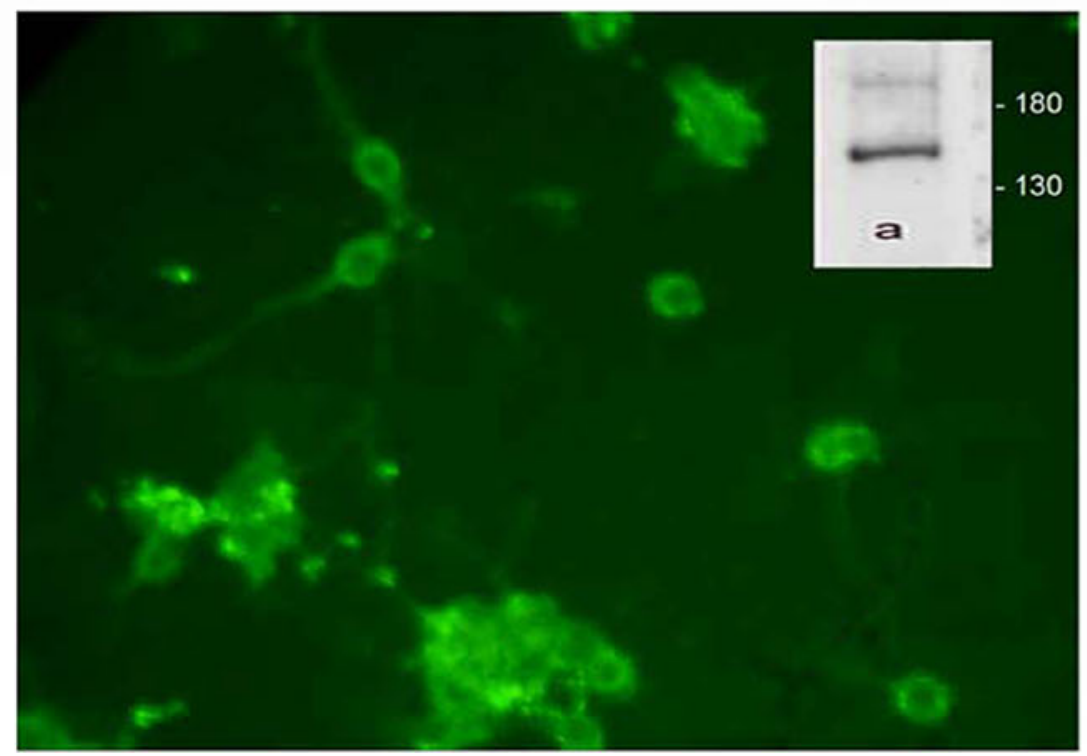

2

2

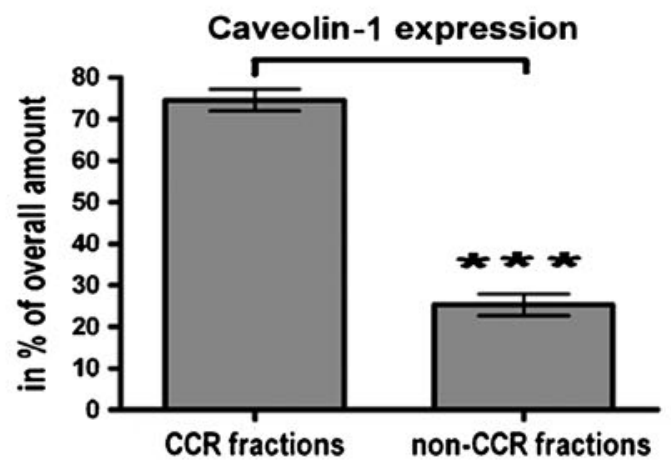

NS Caveolin-1 siRNA
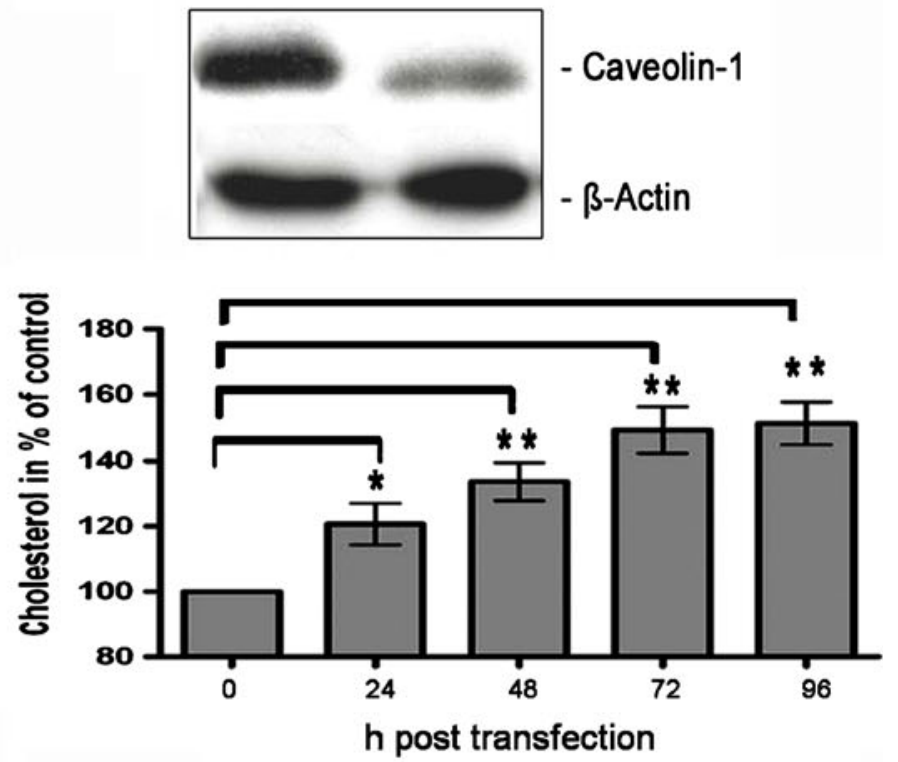
stability of drugs by forming a 1:1 to $2: 1$ inclusion complex (Nishijo et al. 2003; Stella and He 2008); the on/off rates of the equilibrium binding depend on the dilution of the complex (Stella and He 2008). Of the various cyclodextrins present, $\mathrm{M} \beta \mathrm{CD}$ is a useful tool to investigate the function of cholesterol. It sequesters cholesterol in its hydrophobic pocket (Christian et al. 1997) and efficiently removes cholesterol from the plasma membrane which hosts ca. $75 \%$ of the total unesterified cellular cholesterol (Liscum and Munn 1999). Keratinocytes exposed to higher concentrations of $\mathrm{M} \beta \mathrm{CD}$ ( $>50 \%$ cholesterol depletion) for a longer period of time (24 h) undergo a substantial cell death probably by inducing an apoptotic pathway via caspases (Schönfelder et al. 2006; Mahammad et al. 2010). Pig OL were tolerant to a mild depletion of cholesterol $(25 \%)$ via $\mathrm{M} \beta \mathrm{CD}$ over 3 days. OL retracted their processes and aggregated but remained attached to the Petri dish. However, after removal of $\mathrm{M} \beta \mathrm{CD}$ and addition of cholesterol to the medium the cell clumps dispersed. An oligodendroglial-specific labeling showed that the cells present were still OL; a substantial cell death has not occurred. The observed cell aggregation has probably been attributed to the cholesterol depletion and not to an $\mathrm{M} \beta \mathrm{CD}$ effect per se. This assumption is supported by the finding that OL start to detach from the Petri dish after simple removal of $\mathrm{M} \beta \mathrm{CD}$ from the cell medium without replenishing cholesterol. Similarly, in a study on T cells, where limited cholesterol depletion caused an aggregation of lipid rafts, an unspecific effect of M $\beta C D$ could be excluded (Mahammad et al. 2010). Cholesterol plays a crucial role in plasma membrane organization (Pucadyil and Chattopadhyay 2006). Hence, a cholesterol depletion can result in a plasma membrane reorganization, aggregation of lipid rafts, altered growth factor receptor function, enhanced protein expression or suppressed cell migration depending on the cell type investigated (Westover et al. 2003; Jeon et al. 2010; Mahammad et al. 2010). Which of these effects are finally involved in the observed aggregation of OL remains to be investigated.

\section{Rapid Depletion of Cholesterol Impaired NGF Signaling}

The depletion of cholesterol from the plasma membrane by $\mathrm{M} \beta \mathrm{CD}$ disrupts caveolae and interferes with their functionality (Hailstones et al. 1998; Thorn et al. 2003).

Pig OL pre-treated with $10 \mathrm{mM} \mathrm{M} \beta C D$ for $45 \mathrm{~min}$ showed that a lack of cholesterol provoked a compromised oligodendroglial process formation via NGF as well as an inhibition of downstream components of the NGF signaling such as p42/44 MAPK activity. In PC12 cells, a depletion of membrane cholesterol decreased the magnitude and duration of NGFstimulated p42/44 MAPK as well as the phosphorylation of TrkA (Peiro et al. 2000; Limpert et al. 2007). Repletion of cholesterol in PC12 cells restored their ability to activate MAPK upon NGF stimulation (Peiro et al. 2000). Previous results on OL treated with simvastatin, an inhibitor of the cholesterol synthesis, revealed an impairment of myelin components in vitro and a retardation of ongoing remyelination in vivo (Klopfleisch et al. 2008). This effect was in part attributable to a diminished prenylation of small G-proteins but also to a cholesterol depletion indicating a central role of cholesterol for myelination (Saher and Simons 2010).

A reason for these findings might be that cholesterol is involved in the formation of rafts/caveolae. Depletion of cholesterol from caveola-rich membranes, which are linked to the cytoskeleton (Stahlhut and van Deurs 2000), leads to increased membrane stiffness (Kwik et al. 2003; Byfield et al. 2004), a functional disruption of lipid rafts (Thorn et al. 2003) with a dramatic change of the membrane raft proteome (Zheng et al. 2011), caused by a dissociation of signaling proteins from caveolae, a disassembly of caveolin multimeres (Westermann et al. 2005) and flattening of caveolae (Westermann et al. 2005; Fielding and Fielding 2006; Thomas and Smart 2008). Signaling proteins moved to non-raft regions of the plasma membrane, where signaling transmission may be less efficient (Pike 2005).

Downregulation of Caveolin-1 Increases the Oligodendroglial Cholesterol Level

A direct interaction of caveolin-1 and cholesterol had been described by Murata and colleagues (Murata et al. 1995). However, only little is known about the regulation of the cholesterol homeostasis in OL and their function for the oligodendroglial process formation. In particular, the synthesis, the cellular trafficking, uptake, and efflux are not yet understood completely despite the fact that $\mathrm{OL}$ are, besides astrocytes, the major cholesterol-producing cells in the CNS.

In our study, we found that a knockdown of caveolin-1 resulted in an elevation of cellular cholesterol level. However, this increased cholesterol level was concomitant with a decline of oligodendroglial process formation whether or not OL were exposed to NGF (Schmitz et al. 2010). A rational explanation of these apparently contradictory data would be that caveolin-1 plays a crucial role for the intracellular trafficking of cholesterol. The transport of newly synthesized cholesterol to the plasma membrane may be impaired by the low caveolin-1 level. Depletion of cholesterol from the plasma membrane attenuates cellular signaling (Pike 2005). The exact mechanism by which cholesterol efflux and cholesterol transport to the plasma membrane is regulated is as yet not completely understood.

Previous studies had already suggested a role of caveolin1 and CCR in maintaining the cellular cholesterol balance (Roy et al. 1999; Ikonen and Parton 2000; Fielding and Fielding 2000). Caveolin-1 has been found to play a crucial role in non-vesicular cholesterol trafficking. In particular, it may be involved in the trafficking of newly synthesized 
cholesterol from the ER to the plasma membrane (Smart et al. 1996; Incardona and Eaton 2000) which would support our assumption. Caveolin-1 might form a kind of chaperon complex (Uittenbogaard et al. 1998). This complex could already be isolated. It comprised of cholesterol, caveolin-1, cyclophilin (cyp) A, cyp 40, and heat shock protein 56 (Uittenbogaard et al. 1998).

Other findings indicate a role of CCR in cholesterol transport. Relevant cholesterol transport proteins such as LDLRApER-2 or the scavenger receptor class B type1 (SR-BI) are associated with CCR (Babitt et al. 1997; Graf et al. 1999; Matveev et al. 1999; Frank et al. 2002). Overexpression of SR-BI and caveolin-1 significantly increased cholesterol efflux in other cells (Truong et al. 2010). In addition, ATPbinding cassette transporters, which can regulate the transport and efflux of cholesterol across the plasma membrane, are located in CCR (Mendez et al. 2001; Jodoin et al. 2003). However, it remains to be shown which of these transport pathways exist in pig OL.

Interestingly, we could show that another potential "team player" in cholesterol homeostasis is expressed in OL: NPC1L1, a protein involved in cholesterol uptake and transport (Altmann et al. 2004; Betters and Yu 2010). Its putative MW of $\sim 145 \mathrm{kDa}$ as shown by Western blotting and its immunocytochemical localization correspond to results for other tissues (Davies et al. 2005; Temel et al. 2007; Yu et al. 2006). Studies on hepatoma cells have revealed that NPC1L1 is predominantly localized to intracellular components but relocated to the plasma membrane when acute cholesterol depletion via $\mathrm{M} \beta \mathrm{CD}$ occurred (Yu et al. 2006). The NPC1L1-mediated cholesterol uptake seems to occur via a cholesterol-regulated clathrin-dependent endocytosis (Betters and Yu 2010; Yu et al. 2006). NPC1L1 mRNA has been found with highest values in the intestine with variant expression in rodent and human liver indicating species differences; other tissues such as the lung or brain also expressed NPC1L1 but at a relatively low level (Davies et al. 2000, 2005; Pramfalk et al. 2011).

The presence of NPC1L1 in OL is remarkable for the following reasons: (1) It would be of interest to know as to whether NPC1L1 is upregulated during myelinogenesis, a period of highest cholesterol demand since cholesterol synthesis requires substantial energy input (Temel et al. 2007); (2) NPC1L1 is regulated via SREBP2 (Sterol Regulatory Element Binding Protein) which is linked to the MAPK cascade (Kotzka et al. 2000; Pramfalk et al. 2011); MAPK in turn are stimulated by various growth factors active during oligodendroglial maturation and subsequent myelinogenesis; (3) it was shown in a previous report that a lack of NPC1L1 activity causes a deregulation of caveolin transport and localization (Davies et al. 2005). Could NPC1L1 also affect the function of caveolin in OL? Having in mind that caveolin containing rafts are important for growth factor signaling (Schmitz et al. 2010) it seems to be a point necessary to be answered.

In conclusion, the present study provides evidence that cholesterol plays an important role in oligodendroglial process formation and signal transduction \pm NGF. Our caveolin-1 knockdown data indicate a crucial involvement of caveolin1 in oligodendroglial cellular cholesterol trafficking.

Acknowledgments We are grateful to Sabine Kloeppner for her technical assistance and Ludwig Kolb for the graphical design.

Open Access This article is distributed under the terms of the Creative Commons Attribution License which permits any use, distribution, and reproduction in any medium, provided the original author(s) and the source are credited.

\section{References}

Abulrob A, Giuseppin S, Andrade MF, McDermid A, Moreno M, Stanimirovic D (2004) Interactions of EGFR and caveolin-1 in human glioblastoma cells: evidence that tyrosine phosphorylation regulates EGFR association with caveolae. Oncogene 23:69676979

Althaus HH, Montz H, Neuhoff V, Schwartz P (1984) Isolation and cultivation of mature oligodendroglial cells. Naturwissenschaften 71:309-315

Althaus HH, Schröter J, Spoerri P et al (1991) Protein kinase C stimulation enhances the process formation of adult oligodendrocytes and induces proliferation. J Neurosci Res 29:481-489

Althaus HH, Klöppner S, Schmidt-Schultz T, Schwartz P (1992) Nerve growth factor induces proliferation and enhances fiber regeneration in oligodendrocytes isolated from adult pig brain. Neurosci Lett 135:219-223

Althaus HH, Hempel R, Klöppner S et al (1997) Nerve growth factor signal transduction in mature pig oligodendrocytes. J Neurosci Res 50:729-742

Althaus HH, Siepl C (1997) Oligodendrocytes isolated from adult pig brain synthesise and release prostaglandins. Cell Tissue Res 287:135-141

Althaus HH (2004) Remyelination in multiple sclerosis: a new role for neurotrophins? Prog Brain Res 146:415-432

Althaus HH, Klöppner S (2006) Mature pig oligodendrocytes rapidly process human recombinant pro-nerve growth factor and do not undergo cell death. J Neurochem 98:506-517

Althaus HH, Klöppner S, Klopfleisch S, Schmitz M (2008) Oligodendroglial cells and neurotrophins: a polyphonic cantata in major and minor. J Mol Neurosci 35:65-79

Altmann SW, Davis HR Jr, Zhu LJ et al (2004) Niemann-Pick C1 Like 1 protein is critical for intestinal cholesterol absorption. Science 303:1201-1204

Amundson DM, Zhou M (1999) Fluorometric method for the enzymatic determination of chol. J Biochem Biophys Methods 38:4352

Babitt J, Trigatti B, Rigotti A et al (1997) Murine SR-BI, a high density lipoprotein receptor that mediates selective lipid uptake, is Nglycosylated and fatty acylated and colocalizes with plasma membrane caveolae. J Biol Chem 272:13242-13249

Betters JL, Yu L (2010) NPC1L1 and cholesterol transport. FEBS Lett 584:2740-2747

Bist A, Fielding PE, Fielding CJ (1997) Two sterol regulatory elementlike sequences mediate up-regulation of caveolin gene 
transcription in response to low density lipoprotein free cholesterol. Proc Natl Acad Sci 94:10693-10698

Björkhem I, Meaney S (2004) Brain cholesterol: long secret life behind a barrier. Arterioscler Thromb Vasc Biol 24:806-815

Brown DA, London E (1998) Functions of lipid rafts in biological membranes. Annu Rev Cell Dev Biol 14:111-136

Bürgisser P, Althaus HH, Rohmann A, Neuhoff V (1988) Lipid synthesis by oligodendrocytes from adult pig brain maintained in a long-term culture. Neurochem Int 13:111-118

Byfield FJ, Aranda-Espinoza H, Romanenko VG, Rothblat GH, Levitan I (2004) Cholesterol depletion increases membrane stiffness of aortic endothelial cells. Biophys J 87:3336-3343

Chang WJ, Rothberg KG, Kamen BA, Anderson RG (1992) Lowering the cholesterol content of MA104 cells inhibits receptor-mediated transport of folate. J Cell Biol 118:63-69

Christian AE, Haynes MP, Phillips MC, Rothblat GH (1997) Use of cyclodextrins for manipulating cellular cholesterol content. J Lipid Res 38:2264-2272

Davies JP, Levy B, Ioannou YA (2000) Evidence for a Niemann-Pick C (NPC) gene family: identification and characterization of NPC1L1. Genomics 65:137-145

Davies JP, Scott C, Oishi K, Liapis A, Ioannou YA (2005) Inactivation of NPC1L1 causes multiple lipid transport defects and protects against diet-induced hypercholesterolemia. J Biol Chem 280:12710-12720

Dietschy JM, Turley SD (2004) Thematic review series: brain lipids. Cholesterol metabolism in the central nervous system during early development and in the mature animal. J Lipid Res 45:1375-1397

Dreja K, Voldstedlund M, Vinten J, Tranum-Jensen J, Hellstrand P, Swärd K (2002) Cholesterol depletion disrupts caveolae and differentially impairs agonist-induced arterial contraction. Arterioscler Thromb Vasc Biol 22:1267-1272

Dyer CA, Matthieu JM (1994) Antibodies to myelin/oligodendrocytespecific protein and myelin/oligodendrocyte glycoprotein signal distinct changes in the organization of cultured oligodendroglial membrane sheets. J Neurochem 62:777-787

Epand RM, Sayer BG, Epand RF (2005) Caveolin scaffolding region and cholesterol-rich domains in membranes. J Mol Biol 345:339350

Fielding CJ, Bist A, Fielding PE (1997) Caveolin mRNA levels are upregulated by free cholesterol and down-regulated by oxysterols in fibroblast monolayers. Proc Natl Acad Sci 94:3753-3758

Fielding CJ, Bist A, Fielding PE (1999) Intracellular cholesterol transport in synchronized human skin fibroblasts. Biochemistry 38:25062513

Fielding CJ, Fielding PE (2000) Cholesterol and caveolae: structural and functional relationships. Biochim Biophys Acta 1529:210 222

Fielding CJ, Fielding PE (2006) Role of cholesterol in signal transduction from caveolae. In: Fielding CJ (ed) Lipid rafts and caveolae. Wiley-VCH GmbH, Weinheim, pp 91-113

Frank PG, Marcel YL, Connelly MA et al (2002) Stabilization of caveolin-1 by cellular cholesterol and scavenger class B type I. Biochemistry 41:11931-11940

Furuchi T, Anderson RG (1998) Cholesterol depletion of caveolae causes hyperactivation of extracellular signal-related kinase (ERK). J Biol Chem 273:21099-21104

Gamble W, Vaughan M, Kruth HS, Avigan J (1978) Procedure for determination of free and total cholesterol in micro- or nanogram amounts suitable for studies with cultured cells. J Lipid Res 19:1068-1070

Ge S, Pachter JS (2004) Caveolin-1 knockdown by small interfering RNA suppresses responses to the chemokine monocyte chemoattractant protein-1 by human astrocytes. J Biol Chem 279:6688-6695

Gielen E, Baron W, Vandeven M, Steels P, Hoekstra D, Ameloot M (2006) Rafts in oligodendrocytes: evidence and structure-function relationship. Glia 54:499-512
Goritz C, Mauch DH, Pfrieger FW (2005) Multiple mechanisms mediate cholesterol-induced synaptogenesis in a CNS neuron. Mol Cell Neurosci 29:190-201

Graf GA, Connell PM, van der Westhuyzen DR, Smart EJ (1999) The class B, type I scavenger receptor promotes the selective uptake of high density lipoprotein cholesterol ethers into caveolae. J Biol Chem 274:12043-12048

Haeffner EW, Hoffmann CJ, Stoehr M, Scherf H (1984) Cholesterolinduced growth stimulation, cell aggregation, and membrane properties of ascites tumor cells in culture. Cancer Res 44:26682676

Hailstones D, Sleer LS, Parton RG, Stanley KK (1998) Regulation of caveolin and caveolae by cholesterol in MDCK cells. J Lipid Res 39:369-379

Huang CS, Zhou J, Feng AK et al (1999) Nerve growth factor signaling in caveolae-like domains at the plasma membrane. J Biol Chem 51:36707-36714

Ikonen E, Parton RG (2000) Caveolins and cellular cholesterol balance. Traffic 1:212-227

Incardona JP, Eaton S (2000) Cholesterol in signal transduction. Curr Opin Cell Biol 12:193-203

Ishitsuka R, Sato SB, Kobayashi T (2005) Imaging lipid rafts. J Biochem 137:249-254

Jeon JH, Kim SK, Kim HJ, Chang J, Ahn CM, Chang YS (2010) Lipid raft modulation inhibits NSCLC cell migration through delocalization of the focal adhesion complex. Lung Cancer 69:165171

Jodoin J, Demeule M, Fenart L et al (2003) P-glycoprotein in bloodbrain barrier endothelial cells: interaction and oligomerization with caveolins. J Neurochem 87:1010-1023

Kotzka J, Müller-Wieland D, Roth G, Kremer L et al (2000) Sterol regulatory element binding proteins (SREBP)-1a and SREBP-2 are linked to the MAP-kinase cascade. J Lipid Res 41:99-108

Klopfleisch S, Merkler D, Schmitz M et al (2008) Negative impact of statins on oligodendrocytes and myelin formation in vitro and in vivo. J Neurosci 28:13609-13614

Kwik J, Boyle S, Fooksman D, Margolis L, Sheetz MP, Edidin M (2003) Membrane cholesterol, lateral mobility, and the phosphatidylinositol 4,5-bisphosphate-dependent organization of cell actin. Proc Natl Acad Sci U S A 100:13964-13969

Laemmli UK (1970) Cleavage of structural proteins during the assembly of the head of bacteriophage T4. Nature 227:680-685

Limpert AS, Karlo JC, Landreth GE (2007) Nerve growth factor stimulates the concentration of TrkA within lipid rafts and extracellular signal-regulated kinase activation though c-Cbl-associated protein. Mol Cell Biol 27:5686-5698

Liscum L, Munn NJ (1999) Intracellular cholesterol transport. Biochim Biophys Acta 1438:19-37

Loftsson T, Brewster ME (2010) Pharmaceutical applications of cyclodextrins: basic science and product development. J Pharm Pharmacol 62:1607-1621

London E, Brown DA (2000) Insolubility of lipids in triton X-100: physical origin and relationship to sphingolipid/cholesterol membrane domains (rafts). Biochim Biophys Acta 1508:182-195

Mahammad S, Dinic J, Adler J, Parmryd I (2010) Limited cholesterol depletion causes aggregation of plasma membrane lipid rafts inducing T cell activation. Biochim Biophys Acta 1801:625-634

Matveev S, van der Westhuyzen DR, Smart EJ (1999) Co-expression of scavenger receptor BI and caveolin-1 is associated with enhanced selective cholesteryl ester uptake in THP-1 makrophages. J Lipid Res 40:1647-1654

Matveev S, Li X, Everson W, Smart EJ (2001) The role of caveolae and caveolin in vesicle-dependent and vesicle-independent trafficking. Adv Drug Deliv Rev 49:237-250

Mauch DH, Nägler K, Schumacher S et al (2001) CNS synaptogenesis promoted by glia-derived cholesterol. Science 294:1354-1357 
Mendez AJ, Lin G, Wade DP, Lawn RM, Oram JF (2001) Membrane lipid domains distinct from cholesterol/sphingomyelin-rich rafts are involved in the ABCA1-mediated lipid secretory pathway. J Biol Chem 276:3158-3166

Monier S, Dietzen DJ, Hastings WR, Lublin DM, Kurzchalia TV (1996) Oligomerization of VIP21-caveolin in vitro is stabilized by long chain fatty acylation or cholesterol. FEBS Lett 388:143149

Murata M, Peranen J, Schreiner R, Wieland F, Kurzchalia TV, Simons K (1995) VIP21/caveolin is a cholesterol-binding protein. Proc Natl Acad Sci 92:10339-10343

Neuhoff V, Philipp K, Zimmer HG, Mesecke A (1979) A simple, versatile, sensitive and volume-independent method for quantitative protein determination which is independent of other external influences. Hoppe Seylers Z Physiol Chem 360:1657-1670

Nishijo J, Moriyama S, Shiota S (2003) Interactions of cholesterol with cyclodextrins in aqueous solution. Chem Pharm Bull 51:12531257

Norton WT, Cammer W (1984) Isolation and characterization of myelin. In: Morell P (ed) Myelin. Plenum Press, New York, pp 147-195

Nieweg K, Schaller H, Pfrieger FW (2009) Marked differences in cholesterol synthesis between neurons and glial cells from postnatal rats. J Neurochem 109:125-134

Paratcha G, Ibanez CF (2002) Lipid rafts and the control of neurotrophic factor signaling in the nervous system: variations on a theme. Curr Opin Neurobiol 12:542-549

Parpal S, Karlsson M, Thorn H, Strålfors P (2001) Cholesterol depletion disrupts caveolae and insulin receptor signaling for metabolic control via insulin receptor substrate-1, but not for mitogenactivated protein kinase control. J Biol Chem 276:9670-9678

Peiro S, Comella JX, Enrich C, Martin-Zanca D, Rocamora N (2000) PC12 cells have caveolae that contain TrkA. Caveolae disrupting drugs inhibit nerve growth factor-induced, but not epidermal growth factor induced, MAPK phosphorylation. J Biol Chem 275:3784637852

Pike LJ (2005) Growth factor receptors, lipid rafts and caveolae: an evolving story. Biochem Biophys Acta 1746:260-273

Pramfalk C, Jiang ZY, Parini P (2011) Hepatic Niemann-Pick C1-like 1. Curr Opin Lipidol 22:225-230

Prevostel C, Alice V, Joubert D, Parker PJ (2000) Protein kinase C (alpha) downregulates through caveolae-dependent traffic to an endosomal compartment. J Cell Sci 113:2575-2584

Pucadyil TJ, Chattopadhyay A (2006) Role of cholesterol in the function and organization of G-protein coupled receptors. Prog Lipid Res 45:295-333

Rao VM, Stella VJ (2003) When can cyclodextrins be considered for solubilization purposes? J Pharm Sci 92:927-932

Roy S, Luetterforst R, Harding A et al (1999) Dominant negative caveolin inhibits H-Ras function by disrupting cholesterol-rich plasma membrane domains. Nat Cell Biol 1:98-105

Saher G, Brügger B, Lappe-Siefke C et al (2005) High cholesterol level is essential for myelin membrane growth. Nat Neurosci 8:468-475

Saher G, Simons M (2010) Cholesterol and myelin biogenesis. Subcell Biochem 51:489-508

Sato SB, Ishii K, Makino A et al (2004) Distribution and transport of cholesterol-rich membrane domains monitored by a membraneimpermeant fluorescent polyethylene glycol-derivatized cholesterol. J Biol Chem 279:23790-23796
Schmitz M, Klöppner S, Klopfleisch S et al (2010) Mutual effects of caveolin and nerve growth factor signaling in pig oligodendrocytes. J Neurosci Res 88:572-588

Schmitz M, Zerr I, Althaus HH (2011) Effect of cavtratin, a caveolin-1 scaffolding domain peptide, on oligodendroglial signaling cascades. Cell Mol Neurobiol 31:991-997

Smart EJ, Ys Y, Donzell WC, Anderson RGW (1996) A role for caveolin in transport of cholesterol from endoplasmic reticulum to plasma membrane. J Biol Chem 271:29427-29435

Schönfelder U, Radestock A, Elsner P, Hipler UC (2006) Cyclodextrininduced apoptosis in human keratinocytes is caspase- 8 dependent and accompanied by mitochondrial cytochrome c release. Exp Dermatol 15:883-890

Song KS, Li S, Okamoto T, Quilliam LA, Sargiacomo M, Lisanti MP (1996) Co-purification and direct interaction of Ras with caveolin, an integral membrane protein of caveolae microdomains. Detergent-free purification of caveolae microdomains. J Biol Chem 271:9690-9697

Stahlhut M, van Deurs B (2000) Identification of filamin of a novel ligand for caveolin-1: evidence for the organization of caveolin-1associated membrane domains by the actin cytoskeleton. Mol Biol Cell 11:325-337

Stella VJ, He Q (2008) Cyclodextrins. Toxicol Pathol 36:30-42

Temel RE, Tang W, Ma Y et al (2007) Hepatic Niemann-Pick C1-like 1 regulates biliary cholesterol concentration and is a target of ezetimibe. J Clin Invest 117:1968-1978

Thorn H, Stenkula KG, Karlsson M et al (2003) Cell surface orifices of caveolae and localization of caveolin to the necks of caveolae in adipocytes. Mol Biol Cell 14:3967-3976

Thomas CM, Smart EJ (2008) Caveolae structure and function. J Cell Mol Med 12:796-809

Thyberg J (2002) Caveolae and cholesterol distribution in vascular smooth muscle cells of different phenotypes. J Histochem Cytochem 50:185-195

Truong TQ, Aubin D, Falstrault L, Brodeur MR, Brissette L (2010) SR-BI, CD36, and caveolin-1 contribute positively to cholesterol efflux in hepatic cells. Cell Biochem Funct 28:480-489

Uittenbogaard A, Ying YS, Smart EJ (1998) Characterization of a cytosolic heat-shock protein-caveolin chaperone complex. Involvement in cholesterol trafficking. J Biol Chem 273:65256532

Virdee K, Tolkovsky AM (1995) Activation of p44 and p42 MAP kinases is not essential for the survival of rat sympathetic neurons. Eur J Neurosci 7:2159-2169

Westermann M, Steiniger F, Richter W (2005) Belt-like localisation of caveolin in deep caveolae and its re-distribution after cholesterol depletion. Histochem Cell Biol 123:613-620

Westover EJ, Covey DF, Brockman HL, Brown RE, Pike LJ (2003) Cholesterol depletion results in site-specific increases in epidermal growth factor receptor phosphorylation due to membrane level effects. Studies with cholesterol enantiomers. J Biol Chem 278:51125-51133

Yu L, Bharadwaj S, Brown JM et al (2006) Cholesterol-regulated translocation of NPC1L1 to the cell surface facilitates free cholesterol uptake. J Biol Chem 281:6616-6624

Zheng YZ, Boscher C, Inder KL, Fairbank M, Loo D, Hill MM, Nabi IR, Foster LJ (2011) Differential impact of caveolae and caveolin1 scaffolds on the membrane raft proteome. Mol Cell Proteomics 10(10):M110.007146 